\title{
Implant Stability Change Measurement of Flaplessly Placed Immediate Implant on Mandibular First Molar
}

\author{
Yang-Yeol Tae, DDS ${ }^{1}$, Chan-Ho Jung, DDS ${ }^{1}$, Kwan-Soo Park, DDS, MSD, PhD ${ }^{2 *}$ \\ ${ }^{1}$ Resident, Department of Oral and Maxillofacial Surgery, Inje University Sanggye-Paik Hospital, College of \\ Medicine, Inje University, Seoul, Korea \\ ${ }^{2}$ Associate professor, Department of Oral and Maxillofacial Surgery, Inje University Sanggye-Paik Hospital, \\ College of Medicine, Inje University, Seoul, Korea \\ *Corresponding author: Kwan-Soo Park, Department of Oral and Maxillofacial Surgery, Inje University \\ Sanggye-Paik Hospital, 1342, Dongil-ro, Nowon-gu, Seoul 01757, Korea. \\ Tel: +82-2-950-1161. Fax: +82-2-950-1167. E-mail: OMS_kspark@paik.ac.kr
}

\section{OPEN ACCESS}

pISSN $1229-5418$

eISSN 2671-6623

Implantology 2020; 24(3): 103-116

https://doi.org/10.32542/implantology.202011

Received: July 29, 2020

Revised: August 31,2020

Accepted: September 6, 2020

\section{ORCID}

Yang-Yeol Tae

https://orcid.org/0000-0001-6360-9268

Chan-Ho Jung

https://orcid.org/0000-0002-3967-5238

Kwan-Soo Park

https://orcid.org/0000-0002-0254-279X

Copyright $(\mathcal{C}$ 2020. The Korean Academy of Oral \& Maxillofacial Implantology

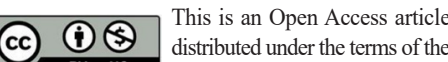
Creative Commons Attribution Non-Commercial License (http://creativecommons. org/licenses/by-nc/4.0/) which permits unrestricted non-commercial use, distribution, and reproduction in any medium, provided the original work is properly cited.

\section{Abstract}

Purpose: This study aims to evaluate the stability change of implants placed immediately after extraction of the mandibular first molar with Resonance Frequency Analysis (RFA).

Materials and Methods: For 24 patients, 25 implants with sandblasted, large grit, and acid-etched (SLA) surface were placed with flapless surgery. Implant stability at implant placement and impression taking procedure were measured with Osstell ISQ. The average interval between implant placement and impression taking was 1.82 months, and implants' success rate was $100 \%$. The average follow-up period was 23.8 months.

Results: The average RFA value of implants measured in all directions increased by 6.4, and the average RFA value measured in the buccolingual direction increased by 5.9. Moreover, the average RFA value measured in the mesiodistal direction increased by 6.9 . There was a statistically significant difference between the buccolingual side's RFA value and the RFA value in the mesiodistal side at implant placement. There was not a completely linear relationship between the RFA value at implant placement and insertion torque.

Conclusion: The change of RFA value can be a useful evaluation method for implant stability of the immediately placed implant after tooth extraction. It may help evaluate the healing of immediately placed implant and determine the appropriate loading time.

Keywords: Resonance frequency analysis, Immediate dental implant, Mandible, Molar

\section{Introduction}

Introduced in the late 1970s, delayed implant placement, which involves placing implants on a healed extraction site, is now widely known as a stable technique with a good prognosis. ${ }^{1}$ According to Hammerle et al., ${ }^{2}$ after tooth extraction, the implant placement delay time can be classified as Type I, II, III, or IV. Immediate placement, which 
involves placing the implant on a fresh extraction site, is considered Type I, and the conventional implant placement method, delayed placement, is Type IV.

The immediate implant placement method is advantageous in that it reduces the number of surgeries a patient undergoes and shortens the length of the treatment period. For anterior dentition in particular, immediate restoration maintains better aesthetics than delayed implant placement, however, there are disadvantages that should be considered. These disadvantages include: the possibility that implants may be placed without pathological issues being healed after extraction, a lack of keratinized gingiva, and the inability to completely seal the soft tissue after implant placement. ${ }^{3}$ Depending on the detailed treatment method, however, immediate placement can have advantages, such as the reduction of soft and hard tissue resorption, and the selection of the optimal position for the implant. Immediate placement of an implant on the posterior dentition also has a number of advantages, and is being occurring more frequently. ${ }^{4}$

The mandibular first molar is the first permanent tooth to erupt, and has a clinically important position in terms of the maintenance of both the arch formation and occlusion, along with a core function during mastication. Loss of the mandibular first molars causes non-physiological occlusion and tipping of adjacent teeth, resulting in extrusion of the antagonistic teeth. ${ }^{5}$ After extraction, notable changes occur at the extraction site, primarily the resorption of about $50 \%$ of buccal bone width, but also a loss of buccal bone height. ${ }^{6}$ It is well known that these side effects can be minimized if implants are immediately placed with gap bone graft after extraction.

Implant stability is defined as having no clinical mobility, and the ability to support the axial, rotational, and lateral loads. ${ }^{7}$ It is important to check initial stability, since increased initial stability after placement affects long-term stability as well as the success rate of the implant. Subsequently, during osseointegration, bone is integrated near the implant thread, so that secondary stability is achieved by gradually increasing contact between bone and the implant. ${ }^{8}$ In particular, it is important to obtain initial and secondary stability when the implant is placed on a fresh extraction site with various bone defects.

Methods for measuring implant stability include histology, removal torque value (RTV) analysis, $\mathrm{X}$-ray imaging, percussion testing, and magnetic resonance frequency analysis (RFA). However, most of these methods are not suitable for long-term clinical evaluation due to invasiveness or accuracy. RFA, a non-contact method, is a bending test of the bone-implant surface. A small magnetic bending force is applied to the side of a transducer mounted on the implant. The displacement, if any, of the implant is measured, confirming the clinical stability of the implant. ${ }^{8}$ With this device, the stability of the implant can be monitored at all stages of treatment. ${ }^{7}$ Predicting the osseointegration of implants or 
deciding load time using RFA value changes are considered positives in various studies. Of these advantages, RFA measurement is considered to be a relatively reliable implant stability measurement method.

Studies regarding RFA change in immediate placements are rare, and to our knowledge, no prior studies have tracked the stability of immediately placed implants with RFA. Performed retrospectively, the present study analyzed the RFA value changes of implants placed immediately after the extraction of the mandibular first molar, in order to evaluate changes in stability and to assist in deciding the load time. We hypothesized that the average RFA value at implant placement in the buccolingual and mesiodistal directions would be consistent.

\section{II . Materials and Methods}

Patients who visited the Department of Oral and Maxillofacial Surgery at Inje University - Sanggye Paik Hospital from August 2012 to October 2019, and who underwent implant placement immediately after the extraction of a mandibular first molar, were selected for this retrospective study. The inclusion criteria were as follows:

1. RFA measurements were obtained during implant placement and impression-taking,

2. Surgery was performed without flap elevation,

3. A bone graft was placed between the implant and the extraction socket, and

4. Vertical loss of the buccal bone at the extraction socket was less than one-third.

In total, 25 implants from 24 patients were included. Tooth extractions were performed to treat dental caries, tooth fractures, and endodontic or periodontal disease. Of the 24 patients, 12 were male and 12 were female, and the average age was 55.58 years (age range: $32-78$ years). The majority $(n=17)$ of the patients were generally healthy, while 6 patients had systemic diseases such as diabetes mellitus (DM), hypertension (HTN), and myocardial infarction (MI), and 1 patient was breastfeeding. From the patients' clinical records, the following types of information were obtained: sex, age, direction of implant, diameter and length of implant, RFA value during implant placement, and dental impressions (Table 1).

Preparation and surgery were performed in accordance with the general protocols as follows: 30 minutes prior to surgery the patient received intravenous antibiotics, after which an inferior alveolar anesthetic nerve block ( $2 \%$ articaine with 1:100,000 epinephrine) was performed, and the tooth was 
carefully extracted. The socket was debrided thoroughly post-extraction, and if necessary, a root dissection was performed to decrease trauma to the extraction socket. A sandblasted and acid-etched (SLA) surface implant was placed in the alveolar septum of the extraction site. If the septum did not exist, the implant was placed in the center of the extraction site. The implant insertion torque was measured in $5 \mathrm{Ncm}$ units, and the insertion was finished in a non-submerged fashion for all implants. The gap between the implant and extraction socket was filled with bone graft material. If necessary, sutures were used to stabilize the peri-implant soft tissue. Postoperative medication was administered, including antibiotics and analgesics. Incision and flap elevations were not performed.

Using the Osstell ISQ scale (Osstell AB, Gothenburg, Sweden), the RFA value was measured during the implant placement and impression-taking, measuring the buccal, lingual, mesial, and distal sides.

\section{Table 1. Demographic data of all patients}

\begin{tabular}{|c|c|c|c|c|c|c|c|c|c|c|c|c|c|}
\hline Number & Gender & Age & * $\mathrm{PMH}$ & Location & Cause of extraction & $\begin{array}{l}\text { Width } \\
(\mathrm{mm})\end{array}$ & $\begin{array}{l}\text { Length } \\
(\mathrm{mm})\end{array}$ & $\begin{array}{c}\text { Graft } \\
\text { material }\end{array}$ & $\begin{array}{l}\text { RFA at } \\
\text { implant } \\
\text { placement }\end{array}$ & $\begin{array}{c}{ }^{* *} \text { RFA at } \\
\text { impression } \\
\text { taking }\end{array}$ & $\begin{array}{l}\text { Period from } \\
\text { implant } \\
\text { placement } \\
\text { to impression } \\
\text { taking (month) }\end{array}$ & $\begin{array}{c}\text { Insertion } \\
\text { torque } \\
\text { (Ncm) }\end{array}$ & $\begin{array}{c}\mathrm{F} / \mathrm{U} \\
\text { period } \\
\text { (month) }\end{array}$ \\
\hline 1 & $\mathrm{~F}$ & 47 & DM & $\# 46$ & Tooth fracture & 5 & 8.5 & Allograft & $62 / 63 / 52 / 53$ & 75/72/72/72 & 2 & 15 & 26 \\
\hline 2 & M & 43 & & $\# 46$ & Periodontal disease & 5 & 10 & Allograft & $53 / 62 / 53 / 53$ & $72 / 68 / 68 / 68$ & 2 & 25 & 79 \\
\hline 3 & M & 59 & DM, HTN, MI & $\# 46$ & Tooth fracture & 5 & 10 & Allograft & 77/77/77/77 & $78 / 80 / 80 / 80$ & 1 & 50 & 56 \\
\hline 4 & $\mathrm{~F}$ & 36 & & $\# 36$ & Dental caries & 5 & 11.5 & Allograft & $74 / 73 / 73 / 73$ & $79 / 80 / 80 / 80$ & 1 & 30 & 6 \\
\hline 5 & $\mathrm{~F}$ & 54 & DM,HTN & $\# 36$ & Dental caries & 5 & 10 & Allograft & $70 / 72 / 70 / 70$ & $83 / 80 / 80 / 80$ & 4 & 25 & 71 \\
\hline 6 & & & & $\# 46$ & Dental caries & 5 & 8.5 & xenograft & 75/75/75/75 & $85 / 80 / 80 / 80$ & 2.5 & 50 & 46 \\
\hline 7 & $\mathrm{~F}$ & 32 & Breast feeding & $\# 46$ & Endodontic disease & 5 & 11.5 & Allograft & $46 / 46 / 46 / 46$ & $67 / 59 / 59 / 59$ & 2.5 & 10 & 6 \\
\hline 8 & $\mathrm{~F}$ & 49 & & $\# 36$ & Periodontal disease & 5 & 11.5 & Allograft & $85 / 85 / 80 / 80$ & 90/90/86 & 1.5 & 35 & 52 \\
\hline 9 & $\mathrm{~F}$ & 58 & & $\# 46$ & Dental caries & 5 & 8.5 & Allograft & $85 / 84 / 82 / 82$ & $84 / 83 / 80 / 83$ & 1.5 & 50 & 7 \\
\hline 10 & $\mathrm{~F}$ & 35 & & $\# 36$ & Tooth fracture & 5 & 11.5 & Xenograft & $49 / 56 / 56 / 56$ & 69/72/72/72 & 2 & 30 & 6 \\
\hline 11 & M & 44 & & $\# 46$ & Tooth fracture & 5 & 10 & Allograft & 77/77/74/74 & $81 / 82 / 80 / 80$ & 2 & 50 & 42 \\
\hline 12 & $\mathrm{~F}$ & 59 & & $\# 36$ & Dental caries & 5 & 8.5 & Xenograft & $80 / 79 / 79 / 79$ & $85 / 85 / 84 / 84$ & 2.5 & 20 & 11 \\
\hline 13 & M & 65 & HTN, lymphoma & $\# 46$ & Dental caries & 5 & 11.5 & Allograft & $85 / 86 / 84 / 86$ & $85 / 83 / 83 / 83$ & 2 & 55 & 36 \\
\hline 14 & M & 76 & HTN, aspirin medi. & $\# 46$ & Dental caries & 4.8 & 10 & Allograft & 77/75/75/75 & $80 / 80 / 80 / 80$ & 1.5 & 30 & 6 \\
\hline 15 & M & 67 & $\begin{array}{l}\text { DM, HTN, aspirin } \\
\text { medi. }\end{array}$ & $\# 46$ & Periodontal disease & 5 & 10 & Allograft & 78/75/75/75 & $80 / 80 / 80 / 80$ & 1.5 & 55 & 6 \\
\hline 16 & $\mathrm{~F}$ & 54 & & $\# 36$ & Endodontic disease & 5 & 10 & Allograft & 78/78/78/78 & $80 / 80 / 80 / 80$ & 2 & 15 & 6 \\
\hline 17 & M & 78 & & $\# 36$ & Tooth fracture & 5.3 & 10 & Allograft & 77/78/75/78 & $85 / 85 / 85 / 85$ & 2 & 35 & 11 \\
\hline 18 & $\mathrm{M}$ & 49 & & $\# 46$ & $\begin{array}{l}\text { anomaly positioned } \\
\text { tooth }\end{array}$ & 5 & 10 & Allograft & $86 / 86 / 82 / 82$ & $87 / 84 / 84 / 84$ & 1 & 15 & 24 \\
\hline 19 & M & 68 & & $\# 36$ & Tooth fracture & 5.5 & 10 & xenograft & 79/79/78/76 & $81 / 81 / 81 / 88$ & 1 & 55 & 23 \\
\hline 20 & $\mathrm{~F}$ & 75 & & $\# 46$ & Dental caries & 4.8 & 8 & Alloplast & $62 / 70 / 70 / 62$ & $74 / 74 / 74 / 74$ & 1 & 20 & 17 \\
\hline 21 & M & 58 & & $\# 36$ & Tooth fracture & 5 & 7 & xenograft & $87 / 75 / 75 / 75$ & $89 / 84 / 84 / 84$ & 2.5 & 55 & 19 \\
\hline 22 & $\mathrm{~F}$ & 64 & & $\# 46$ & Tooth fracture & 4.5 & 8.5 & Allograft & $80 / 77 / 77 / 78$ & $81 / 81 / 80 / 80$ & 2 & 55 & 9 \\
\hline 23 & M & 41 & & \#46 & $\begin{array}{c}\text { Tooth fracture, Dental } \\
\text { caries }\end{array}$ & 5 & 10 & Allograft & $80 / 80 / 79 / 80$ & $83 / 82 / 80 / 82$ & 1 & 20 & 23 \\
\hline 24 & M & 59 & & $\# 46$ & Periodontal disease & 5 & 8 & xenograft & $73 / 67 / 66 / 66$ & $80 / 80 / 80 / 75$ & 2.5 & 30 & 10 \\
\hline 25 & $\mathrm{~F}$ & 64 & & \#46 & $\begin{array}{c}\text { Endodontic, } \\
\text { periodontal disease }\end{array}$ & 5 & 10 & Allograft & $80 / 80 / 74 / 80$ & $82 / 85 / 83 / 85$ & 2.5 & 50 & 6 \\
\hline
\end{tabular}

"PMH : premedical history.

${ }^{* *}$ Four consecutive numbers indicate RFA values measured at buccal side, lingual side, mesial side, and distal side, respectively. 
The RFA values were defined as follows, according to the manufacturer's instructions: average RFA value in all directions (RFA1total), average RFA value in the buccolingual direction (RFA1BL), and average RFA value in the mesiodistal direction (RFA1MD) during implant placement; average RFA value in all directions (RFA2total), average RFA value in the buccolingual direction (RFA2BL), and average RFA value in the mesiodistal direction (RFA2MD) during impression-taking. The average time from implant placement to impression-taking was 1.82 months (range: 1-4 months). The changes in the RFA values between implant placement and impression-taking were verified using the Wilcoxon signed-rank test. SPSS Statistics 25.0 (IBM, USA) was used for statistical analysis.

\section{Results}

Of the 25 implants, 16 replaced the right mandibular first molar, and 9 replaced the left. All implants in all patients healed uneventfully. The average diameter of the implants was $4.996 \mathrm{~mm}$ (range: $4.5-5.5$ $\mathrm{mm}$ ), and the average length of the fixtures was $9.72 \mathrm{~mm}$ (range: $7.0-11.5 \mathrm{~mm}$ ), as seen in Table 1. All

\section{Table 2. Spearman Correlation Coefficient Between RFA1 total and Insertion torque value}

$\begin{array}{llc} & \text { RFAltotal } \\ \text { Insertion torque } & \text { Spearman correlation coefficient } & .335^{*} \\ & \text { Significance } & .102 \\ & \mathrm{~N} & 25\end{array}$

*Denotes low correlation.

The insertion torque and RFA value of implant at placement showed low positive correlation (Spearman correlation coefficient $=0.335)$.

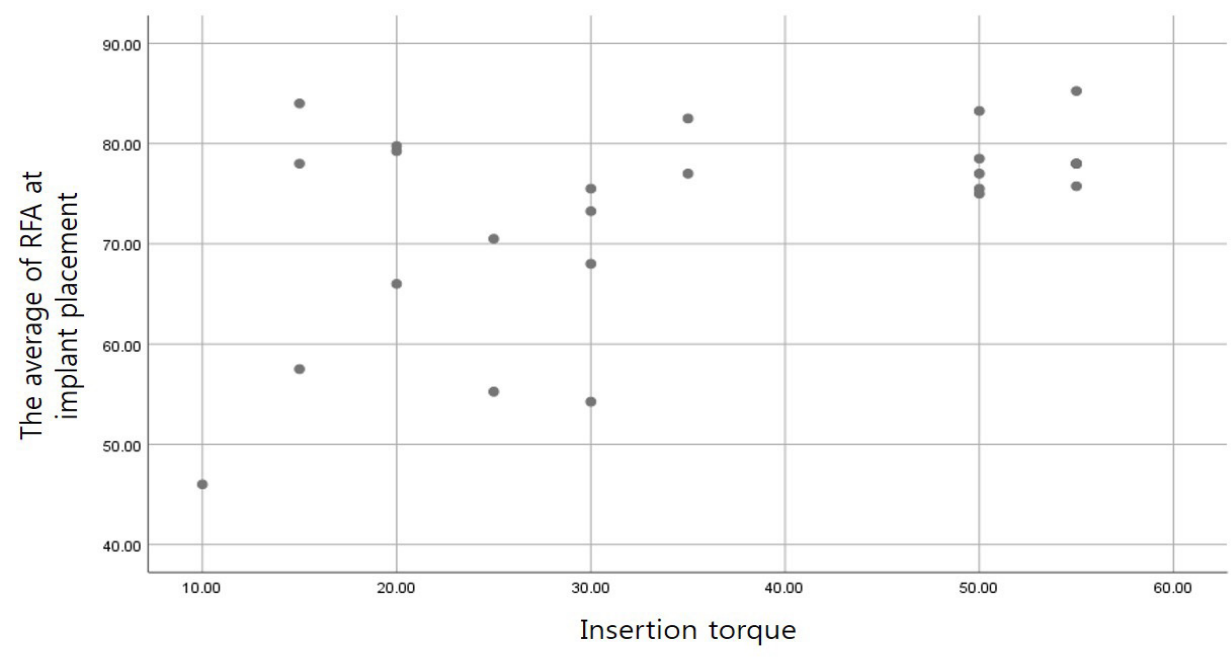

Insertion torque and RFA do not linearly match.

Fig. 1. The scatter plot of relationship between RFA at implant placement and Insertion torque. 
implants were placed via flapless surgery, and soft tissue healing was achieved within 1-2 weeks. The average follow-up period was 24.2 months, during which none of the implants failed. During the impression-taking, all implants except one had RFA values higher than 65 in all directions: buccal, lingual, mesial, and distal (Table 1).

The average insertion torque was $35.2 \mathrm{Ncm}$ (range: $10-55 \mathrm{Ncm}$ ). Spearman's correlation analysis was used to examine the relationship between insertion torque and RFA value during implant placement. This analysis showed a low positive correlation, with a correlation coefficient $=0.335$ (Table 2 and Fig. 1 ).

The average RFA values during implant placement were: all directions (RFA1total) $=73.24$, buccolingual direction $($ RFA1BL $)=74.2$, and mesiodistal direction $($ RFA1MD $)=72.28($ Table 3$)$. The average RFA values during impression-taking were: all directions $($ RFA2total $)=79.64$, buccolingual direction $($ RFA2BL $)=80.1$, and mesiodistal direction $($ RFA2MD $)=79.18($ Table 3$)$. The average RFA values for all directions, the buccolingual direction, and the mesiodistal direction, were increased, with a $p$-value $<0.01$ (Fig. 2).

Table 3. The average RFA value according to direction and measurement time

\begin{tabular}{ccc} 
Direction & RFA at implant placement & RFA at impression taking \\
\hline BLMD & 73.24 (RFA1total) & 79.64 (RFA2total) \\
BL & 74.2 (RFA1BL) & 80.1 (RFA2BL) \\
MD & 72.28 (RFA1MD) & 79.18 (RFA2MD) \\
\hline
\end{tabular}

RFA measurement

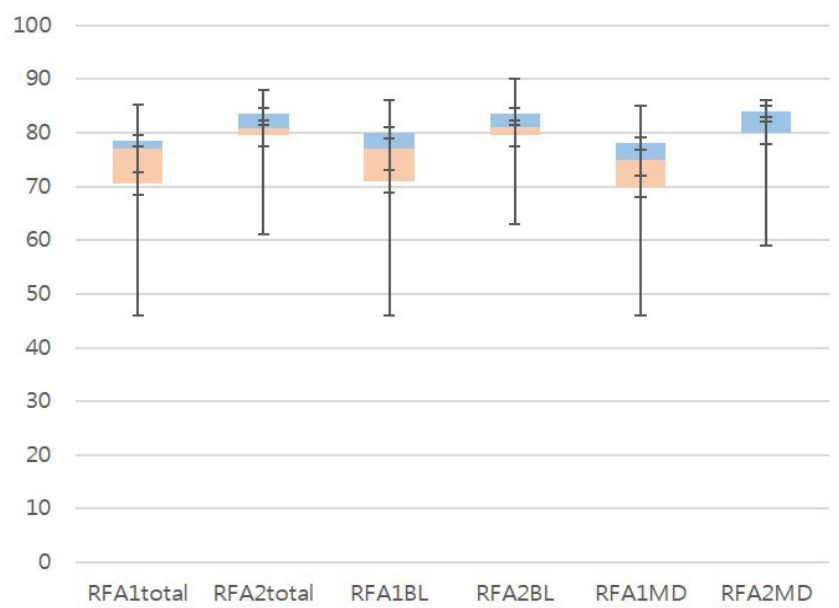

In all direction, in buccolingual side, in mesiodistal side, the average RFA value at implant placement increased at impression taking $(p<0.01)$.

Fig. 2. Average RFA value at implant placement and impression taking in all direction and buccolingual, mesiodistal side. 


\section{IV . Discussion}

The method placing the implant immediately after extraction reduces the number of surgeries and procedures a patient undergoes, maintains alveolar bone height and width, and shortens the duration of the treatment period. ${ }^{10}$ Particularly in the placement of a single anterior implant, the immediate placement method is preferred because it maintains the shape of the buccal bone and soft tissue, and is a single-day restoration process, which does not impair aesthetics. ${ }^{11}$ Even with immediate placement, horizontal and vertical loss of the alveolar ridge cannot be avoided, although there is no visible bone loss affecting the initial stability. ${ }^{12}$ The immediate placement of a single implant in the posterior dentition is more difficult and less useful than for the anterior dentition, however, it can still reduce the duration of the treatment period and may prevent various difficulties and side effects that can occur during delayed placement.

During implant placement, the least invasive technique should generally be used. Although case selection is very important and technique sensitive, ${ }^{13}$ some authors are of the opinion that it is more important to place the implant with as little flap elevation as possible in order to minimize the loss of soft and hard tissue at the site of implant. ${ }^{14}$ Additionally, depending on the number and anatomy of the root and the presence of a septum, the difficulty and consideration for implant placement may change. ${ }^{15}$ There is a controversy regarding whether bone grafts and/or membranes are needed to fill various gaps between the implant and bone. Schwartz-Arad et al. ${ }^{16}$ reported that the survival rate of implants placed immediately after extraction is $93.9-100 \%$, and if placed 3 to $5 \mathrm{~mm}$ below the root apex for initial fixation, gap-filling is not necessary and bone loss is not reduced by using a membrane. Tarnow et al. ${ }^{17}$ reported that if buccal bone is intact, gap-healing can be achieved sufficiently using only a membrane and stable initial sutures, without a bone graft. However, Chen et al, ${ }^{3,18}$ have reported that when a rough surface implant is placed immediately after extraction, $2 \mathrm{~mm}$ or less of horizontal defect can be healed naturally without the use of a graft or a membrane, but that a horizontal defect of more than $2 \mathrm{~mm}$ or a damaged extraction socket requires the use both. In other literature, bone grafts and/or membranes can be applied to regenerate alveolar bone, providing a predictable and high-quality osseointegration. ${ }^{3}$

In practice, the primary stability of dental implants is one of the most important elements of successful osseointegration. ${ }^{19}$ Primary stability involving the mature bone around the extraction site plays a significant role in deciding the success and failure of an implant, especially in the immediate placement method. ${ }^{20}$ Primary stability can also be affected by factors such as bone quality and mass, surgical technique, implant design, and surface treatment. ${ }^{21}$ In general implant placement protocols, increased primary stability can be achieved by using a drill that is smaller than the diameter of the implant, or using a taper implant rather than a parallel implant in low-density bone with poor bone quality. ${ }^{22}$ If necessary, 
these protocols can be used for immediate implant placement to achieve better initial stability.

During implant placement surgery, stability can be measured by manually assessing immobility with the hand or by checking the insertion torque. Given the limitations caused by the invasiveness of the placement, it is common to evaluate immobility using a percussion test or magnetic RFA. Of these options, RFA evaluated immobility using a non-contact method, and therefore has the advantage of being noninvasive. Given this advantage, RFA is the more widely accepted method used to assess immobility. An RFA value that increases over time in an implant placed on a healed ridge can be considered to indicate an increasing stability of the implant, and may also indicate a successful osseointegration. ${ }^{23}$ As a result of osseointegration, mechanical stability then becomes biological stability, which can be determined by using RFA to evaluate the change in implant stability during osseointegration after implant placement.

Currently, there is no consensus on the minimum insertion torque or RFA value which defines a successful implant, ${ }^{1}$ but it is known that there is a close relationship between the success of an implant and RFA value, as well as between success of implant and insertion torque. ${ }^{24}$ Rowan et $\mathrm{al}^{25}$ has found that during implant placement, the average RFA value of implants placed immediately at various sites is lower than the average RFA values of delayed implants. At the postoperative check, however, after successful osseointegration, it has been confirmed that the average RFA values of immediately placed implants were consistently higher than 65 , which was the minimum RFA value indicative of a successful implant. Balleri et al $^{26}$ have found that the RFA values of implants which have successfully undergone osseointegration was 57 to 82 , and the average RFA value 1 year after implantation was 69 . In other studies, an RFA value above 68 can be considered to indicate a high primary stability. ${ }^{27}$ Another previous study has showed that a successful implant has an average insertion torque of $33 \mathrm{Ncm}$ and an average RFA value of $66 .{ }^{28}$ Becker et al. ${ }^{29}$ describes that implants with a low initial stability, determined by RFA measurement after immediate placement, tend to have an initial stability that increases over time, whereas implants with higher RFA values immediately after placement tend to have an initial stability that decreases over time. This suggests that all implants, regardless of the initial RFA value, reach a similar level of stability over time.

The initial stability of a failed implant decreases over time, until it is eventually lost. ${ }^{30} \mathrm{Nedir}^{31} \mathrm{describes}^{3}$ a proposed cutoff RFA value of 47, which indicates the failure of an implant. An RFA value of 47 or higher, therefore, should be considered to indicate a stable implant. According to another study, for 20 of 300 implants that failed, the average insertion torque was $21 \mathrm{Ncm}$ and the average RFA value was $46{ }^{24}$ Repeated RFA measurements at certain intervals after the placement of an implant can assist in 
determining the load time ${ }^{27}$ and predicting early signs of clinical failure. ${ }^{32}$ Removing and connecting the transducer to the implanted fixture to take frequent RFA measurements can actually affect the healing of the implant. Yang et al..$^{23}$, however, reported no significant association between the removal or connection of the implant abutment and marginal bone resorption, implying that stability is not affected. From this, it may be inferred that the repeated removal and/or connection of the transducer does not affect the stability of the implant. Glauser et al. ${ }^{33}$ noted that 1-2 months after implant placement, the RFA value temporarily decreased to approximately 60 . This initial decrease was due to relaxation over time of the compressed bone which resulted from the implant placement. The initial decrease is associated with biological changes and marginal bone resorption which are part of the early healing process. After a 12 month implant stabilization period, the RFA value started to increase again, ${ }^{27,33}$ primarily the result of increased stiffness caused by osseointegration and bone maturation at the implant site. ${ }^{31}$

In the present study, the implant was placed immediately after the extraction of the mandibular first molars with flapless surgery and a gap bone graft. The insertion torque varied from 10 to $55 \mathrm{Ncm}$, as seen in Table 1. Even in the sixth patient, who had the lowest insertion torque, an increased RFA value over 10 was observed in all directions after 2.5 months, at the time of impression-taking, after which stable loading was performed. At the time of the implant placement, the RFA value was over the cutoff value of 47 in all directions (Nedir et al. 2004) for all patients except for one, which indicated implant failure in that patient. At the time of impression-taking, RFA values of 65 or more were observed in all directions in all patients except for one, whose RFA value was 47 or more in all directions. Comparing the average RFA values in all directions during implant placement (RFA1total) to those at the time of impression-taking (RFA2total), it was confirmed that the average RFA value in all directions had increased. Comparing the average RFA values in the buccolingual direction during implant placement (RFA1BL) to those at the time of impression-taking (RFA2BL), it was confirmed that the average RFA value in the buccolingual direction had increased. Comparing the average RFA values in the mesiodistal direction during implant placement (RFA1BL) to those at the time of impression-taking (RFA2BL), it was confirmed that the average RFA value had also increased in the mesiodistal direction. After immediate placement, osseointegration and socket healing were achieved, and subsequently, secondary stability of the implant was obtained. The results of the present study confirmed that the stability of the implant increased as the RFA values increased, regardless of the direction.

The RFA values in the buccolingual and mesiodistal directions during implant placement showed statistically significant differences. It is thought that this is due to the bone-implant contact pattern, which can be formed in a variety of manners as the result of the different extraction socket shapes found 
during immediate implant placement. A higher RFA value was observed in the buccolingual direction than in the mesiodistal direction, which is presumed to be due to the anatomical shape of the region. When an implant is placed in the mandibular first molar region, in the mesiodistal direction there is only a small apical area where alveolar bone is in contact with the implant, but in the buccolingual direction, the implant is placed closely to lingual bone in the extraction socket, creating a wider bone-implant surface. Additionally, the alveolar septum at the extraction site, which can offer primary stability, is often present in the buccolingual direction. This allows for the inference that since bone-implant contact, which affects stability, occurs more in the buccolingual direction, the RFA value would indicate an effect on stability.

Table 2 shows a slight non-linear relationship between insertion torque and RFA value, (Spearman correlation coefficient $=0.335$ ), which is similar to a previous study which indicated that insertion torque and RFA did not have a high correlation. ${ }^{22}$ It seems that in an immediate placement, due to bone defect that remains after the extraction, the bone-implant contact may form differently in the buccolingual and mesiodistal directions, and that the bone-implant contact required for stability may be limited to the root area. RFA and insertion torque represent resistance to two different characteristics of primary stability. RFA represents resistance to bending load, and insertion torque represents resistance to shear force. ${ }^{34}$ These representations are related to the above in terms of stability. Given that the RFA value does not linearly correspond with implant stability, it can be inferred that the relationship between insertion torque and stability as measured by RFA is not completely linear (Fig. 1). Scarano et al. ${ }^{35}$ have found a statistically significant correlation between RFA value and bone-implant contact. In other studies, RFA is related to the height of the portion of the implant which is not surrounded by bone and the stability of the bone-implant surface. Rigidity of the bone-implant surface, bone quality, and the rigidity of the implant component itself all affect the RFA value. ${ }^{36}$ It is thought that the results described above are caused by the differences in bone-implant contact, which can occur during implant placement, and the different principles of each measurement method.

In the present study, there was a delay 1-4 months, with an average time of 1.82 months, between the implant placement and the impression-taking. During of the average 24.2 months of follow-up, there were no implant failures. The authors have therefore tentatively determined the timing of impressiontaking in consideration to the RFA value, insertion torque, and bone-implant contact at placement. The RFA value was measured on the date scheduled for impression-taking, and the decision of whether or not to proceed with the next step was made. Osseointegration of the SLA implant surface with healthy bone was complete after approximately $6-8$ weeks. With the immediate placement method, it may take 
longer for bone formation and osseointegration to occur in the gap of the coronal area. However, if the RFA value is increased, osseointegration is expected to proceed well, particularly where the boneimplant contact is intact or the gap is narrow from the time of placement, such as in the apical area. Therefore, at that time it is appropriate to proceed with the restoration stage for implant loading.

Some patients had systemic diseases, such as DM, HTN, and MI. In general, the primary stability, as indicated by the RFA value, is low in diabetic patients, and if not controlled, the RFA value after 1 year is even lower than that of controlled patients. ${ }^{37}$ Therefore, an individualized plan systemic disease control must be completed prior to implant placement. ${ }^{38}$ In the present study, the initial RFA values and subsequent RFA value increases in patients with systemic diseases were comparable to those in patients without systemic disease. Although the present study only included small number of patients, it can still be expected that if a systemic disease is well controlled in patients who undergo an immediate implant placement after extraction, the disease is unlikely to affect the primary and secondary stability of the implant.

The biggest limitation to the present study was the small number of patients included in the study population. The differing lengths and widths of the implants make it rather difficult to confirm an association with RFA values in this regard. There is also the limitation due to the inconsistent time between the implant procedure and the impression-taking. Another limitation is that the marginal bone level changes were not measured, and it is thought to be helpful to confirm long-term success by measuring these changes. In addition, a few cases with short follow-up periods have been included, and it is therefore difficult to confirm the long-term stability and prognosis of implants in some of these cases. Under limited conditions, the RFA values tended to increase with the immediate placement of the implant after the extraction of the mandibular first molar and showed stable clinical results. Compared to the delayed placement method, the bone gap at the extraction site and the irregularity of bone-implant contact are potential complications with the immediate placement method. Whether bone grafting is performed or not, how much these bone gaps affect the osseointegration and healing period of implants, and when to apply loading remain concerns for many clinicians when assessing immediate versus delayed placement. The results of the present study indicate that the RFA values of implants placed immediately after the extraction of the mandibular first molar tend to increase, as is seen with the delayed placement method. 


\section{Conclusion}

Although the amount of data is limited in the study, an RFA value which increases over time could be used as an indicator to help evaluate the healing of the implant and to determine the load time after the immediate placement of the implant after the extraction of mandibular first molar. Further studies with larger study populations are needed in the future.

\section{References}

1. Atalay B, Öncü B, Emes Y, Bultan Ö, Aybar B, Yalçin S. Immediate implant placement without bone grafting: a retrospective study of 110 cases with 5 years of follow-up. Implant Dent 2013;22:360-5.

2. Hammerle $\mathrm{CH}$, Chen ST, Wilson TG, Jr. Consensus statements and recommended clinical procedures regarding the placement of implants in extraction sockets. Int J Oral Maxillofac Implants 2004;19: 26-8.

3. Chen ST, Wilson Jr TG, Hämmerle CHF. Immediate or early placement of implants following tooth extraction: review of biologic basis, clinical procedures, and outcomes. Int J Oral Maxillofac Implants 2004;19:12-25.

4. Lindeboom JAH, Tjiook Y, Kroon FHM. Immediate placement of implants in periapical infected sites: a prospective randomized study in 50 patients. Oral Surg Oral Med Oral Pathol Oral Radiol Endod 2006;101:705-10.

5. Carvalho W, Casado PL, Caúla AL, Barboza EP. Implants for single first molar replacement: important treatment concerns. Implant Dent 2004;13:328-35.

6. Botticelli D, Persson LG, Lindhe J, Berglundh T. Bone tissue formation adjacent to implants placed in fresh extraction sockets: an experimental study in dogs. Clin Oral Implants Res 2006;17:351-8.

7. Andreotti AM, Goiato MC, Nobrega AS, da Silva EVF, Filho HG, Pellizzer EP, et al. Relationship between implant stability measurements obtained by two different devices: a systematic review. J Periodontol 2017;88:281-8.

8. Rodrigo D, Aracil L, Martin C, Sanz M. Diagnosis of implant stability and its impact on implant survival: a prospective case series study. Clin Oral Implants Res 2010;21:255-61.

9. Huang HM, Lee SY, Yeh CY, Lin CT. Resonance frequency assessment of dental implant stability with various bone qualities: a numerical approach. Clin Oral Implants Res 2002;13:65-74.

10. Botticelli D,Berglundh T. Lindhe J. Hard-tissue alterations following immediate implant placement in extraction sites. J Clin Periodontol 2004;31:820-8.

11. Evans CDJ, Chen ST. Esthetic outcomes of immediate implant placements. Cli Oral implants Res 2008; 19:73-80.

12. Mello CC, Lemos CAA, Verri FR, Dos Santos DM, Goiato MC, Pellizzer EP. Immediate implant placement into fresh extraction sockets versus delayed implants into healed sockets: a systematic review and meta-analysis. Int J Oral Maxillofac Surg 2017;46:1162-77.

13. Chen ST, Darby IB, Reynolds EC, Clement JG. Immediate implant placement postextraction without flap elevation. J Periodontol 2009;80:163-72.

14. Schwartz-Arad D, Chaushu G. Immediate implant placement: a procedure without incisions. J 
Periodontol 1998;69:743-50.

15. Smith RB, Tarnow DP. Classification of molar extraction sites for immediate dental implant placement. Int J Oral Maxillofac Implants 2013;28:911-6.

16. Schwartz-Arad D, Chaushu G. The ways and wherefores of immediate placement of implants into fresh extraction sites: a literature review. J Periodontol 1997;68:915-23.

17. Tarnow DP, Chu SJ, Salama MA, Stappert CF, Salama H, Garber DA, et al. Flapless postextraction socket implant placement in the esthetic zone: part 1. The effect of bone grafting and/or provisional restoration on facial-palatal ridge dimensional change-a retrospective cohort study. Int J Periodontics Restorative Dent 2014;34:323-31.

18. Esposito M, Grusovin MG, Felice P, Karatzopoulos G, Worthington HV, Coulthard P. Interventions for replacing missing teeth: bone augmentation techniques for dental implant treatment. Cochrane Database Syst Rev 2009;4:CD003607.

19. Gapski R, Wang HL, Mascarenhas P, Lang NP. Critical review of immediate implant loading. Clin Oral Implants Res 2003;14:515-27.

20. Javed F, Romanos GE. The role of primary stability for successful immediate loading of dental implants. A literature review. J Dent 2010;38:612-20.

21. Atieh MA, Alsabeeha NHM, Payne AGT, de Silva RK, Schwass DS, Duncan WJ. The prognostic accuracy of resonance frequency analysis in predicting failure risk of immediately restored implants. Clin Oral Implants Res 2014;25:29-35.

22. Degidi M, Daprile G, Piattelli A. Primary stability determination by means of insertion torque and RFA in a sample of 4,135 implants. Clin Implant Dent Relat Res 2012;14:501-7.

23. Yang SM, Shin SY, Kye SB. Relationship between implant stability measured by resonance frequency analysis (RFA) and bone loss during early healing period. Oral Surg Oral Med Oral Pathol Oral Radiol Endod 2008; 105:e12-9.

24. Turkyilmaz I, Mcglumphy EA. Influence of bone density on implant stability parameters and implant success: a retrospective clinical study. BMC Oral Health 2008;8:1-8.

25. Rowan M, Lee D, Pi-Anfruns J, Shiffler P, Aghaloo T, Moy PK. Mechanical versus biological stability of immediate and delayed implant placement using resonance frequency analysis. Int J Oral Maxillofac Surg 2015;73.2:253-7.

26. Balleri P, Cozzolino A, Ghelli L, Momicchioli G, Varriale A. Stability measurements of osseointegrated implants using Osstell in partially edentulous jaws after 1 year of loading: a pilot study. Clin Implant Dent Relat Res 2002;4:128-32.

27. Glauser R, Sennerby L, Meredith N, Rée A, Lundgren AK, Gottlow J, et al. Resonance frequency analysis of implants subjected to immediate or early functional occlusal loading: successful vs. failing implants. Clin Oral Implants Res 2004;15:428-34.

28. Kahraman S, Bal BT, Asar NV, Turkyilmaz I, Tözüm TF. Clinical study on the insertion torque and wireless resonance frequency analysis in the assessment of torque capacity and stability of selftapping dental implants. J Oral Rehabil 2009;36:755-61.

29. Becker W, Sennerby L, Bedrossian E, Becker BE, Lucchini JP. Implant stability measurements for implants placed at the time of extraction: a cohort, prospective clinical trial. J Periodontol 2005;76:391-7.

30. da Cunha HA, Francischone CE, Filho HN, de Oliveira RCG. A comparison between cutting torque and resonance frequency in the assessment of primary stability and final torque capacity of standard and TiUnite single-tooth implants under immediate loading. Int J Oral Maxillofac Implants 
2004;19:578-85.

31. Nedir R, Bischof M, Szmukler-Moncler S, Bernard JP, Samson J. Predicting osseointegration by means of implant primary stability: a resonance-frequency analysis study with delayed and immediately loaded ITI SLA implants. Clin Oral Implants Res 2004;15:520-8.

32. Meredith N, Books K, Fribergs B, Jemt T, Sennerby L. Resonance frequency measurements of implant stability in viva. A cross-sectional and longitudinal study of resonance frequency measurements on implants in the edentulous and partially dentate maxilla. Clin Oral Implants Res 1997;8:226-33.

33. Glauser R, Lundgren AK, Gottlow J, Sennerby L, Portmann M, Ruhstaller P. Immediate occlusal loading of Brånemark TiUnite ${ }^{\mathrm{TM}}$ implants placed predominantly in soft bone: 1-year results of a prospective clinical study. Clin Implant Dent Relat Res 2003;5:47-56.

34. Sennerby L, Meredith N. Implant stability measurements using resonance frequency analysis: biological and biomechanical aspects and clinical implications. Periodontology 2000 2008;47:5166.

35. Scarano A, Degidi M, Iezzi G, Petrone G, Piattelli A. Correlation between implant stability quotient and bone-implant contact: a retrospective histological and histomorphometrical study of seven titanium implants retrieved from humans. Clin Implant Dent Relat Res 2006;8:218-22.

36. Zix J, Kessler-Liechti G, Mericske-Stern R. Stability measurements of 1-stage implants in the maxilla by means of resonance frequency analysis: a pilot study. Int J Oral Maxillofac Implants 2005;20:747-52.

37. Oates TW, Galloway P, Alexander P, Green AV, Huynh-Ba G, Feine J, et al. The effects of elevated hemoglobin A1c in patients with type 2 diabetes mellitus on dental implants. J Am Dental Assoc 2014;145:1218-26.

38. Diz P, Scully C, Sanz M. Dental implants in the medically compromised patient. J Dent 2013;41:195206. 